\title{
A Conformational Model for MTPA Esters of Chiral $N$-(2-Hydroxyalkyl)acrylamides
}

\author{
Eduardo M. Rustoy, ${ }^{1}$ Alicia Baldessari, ${ }^{1}$ and Leandro N. Monsalve ${ }^{1,2}$ \\ ${ }^{1}$ Laboratorio de Biocatálisis, Departamento de Química Orgánica y UMYMFOR, Facultad de Ciencias Exactas y Naturales, \\ Universidad de Buenos Aires, Pabellón 2, Piso 3, Ciudad Universitaria, C1428EGA Buenos Aires, Argentina \\ ${ }^{2}$ INTI-CONICET, Avenida Gral. Paz 5445, Ed. 42, San Martín, B1650JKA Buenos Aires, Argentina
}

Correspondence should be addressed to Leandro N. Monsalve; monsalve@inti.gob.ar

Received 19 May 2014; Revised 13 July 2014; Accepted 13 July 2014; Published 10 August 2014

Academic Editor: Daniel Glossman-Mitnik

Copyright (C) 2014 Eduardo M. Rustoy et al. This is an open access article distributed under the Creative Commons Attribution License, which permits unrestricted use, distribution, and reproduction in any medium, provided the original work is properly cited.

The absolute stereochemistry of novel chiral $N$-(2-hydroxylalkyl)acrylamides prepared by a lipase-catalyzed resolution was successfully determined by ${ }^{1} \mathrm{H}$ NMR of their MTPA esters. The method was validated for this particular case by computational experiments.

\section{Introduction}

It is well known that chiral acrylamides are useful compounds in organic synthesis [1-3].

The absolute stereochemistry of chiral compounds is determined by using several methods [4]. Among the methods available, NMR spectroscopy using chiral derivatizing agents such as 2-methoxy-2-(trifluoromethyl)phenylacetic acid (MTPA) has been widely used in the determination of configuration of stereogenic centers bearing either hydroxyl or amine groups. More recently, this methodology has been applied for the derivatization of chiral primary alcohols thus determining the absolute configuration of stereogenic centers at a two- and three-bond distance from the hydroxyl group [5-8]. Moreover, the modified Mosher's method has been used to determine the absolute configuration of primary alcohols with chiral methyl groups at C-2 [9].

However, it should be noted that this modification of Mosher's method seemed to be unsuccessful for determining their stereochemistry of MTPA esters of some simple C-2 branched primary alcohols with conjugated groups or a consecutive chiral centre at C-3. According to Tsuda et al. the difference in chemical shift between diastereotopic oxymethylene protons is similar for both diastereomers [9].

We have previously performed a lipase-catalyzed synthesis of nonchiral and chiral $N$-(2-hydroxyalkyl)acrylamides (Scheme 1) $[10,11]$.
We employed the modified Mosher's method for the determination of \%ee. The absolute configuration of products was found to be $(S)$. However, a report by Puertas et al. [12] describes the enantioselective behavior of Candida antarctica lipase B (CAL B) affording the $(R)$-acrylamides instead of $(S)$ acrylamides as products, using racemic amines as starting materials.

Considering the absence of a conformational model for MTPA esters of $\beta$-chiral primary alcohols and the results of our experiments showing opposite selectivity to previous experience, we decided to test the reliability of the method for our case. The aim of this work was to validate the results by conformational analysis of MTPA esters and thus obtain a reasonable explanation for NMR data on a molecular basis.

\section{Results and Discussion}

We performed the synthesis of chiral N-(2-hydroxyalkyl)acrylamides $\mathbf{2 a}-\mathbf{d}$ and their corresponding MTPA esters $\mathbf{3 a}-\mathbf{d}$ and $\mathbf{4 a -} \mathbf{d}$ as described in order to assign their absolute stereochemistry and the degree of stereoselectivity achieved in each case (Scheme 2).

After purification, the MTPA esters were analyzed by ${ }^{1} \mathrm{H}$ NMR spectroscopy in $\mathrm{CDCl}_{3}$. The results observed for compounds (S)-3b and (S)-4b were taken as example and showed significant differences in the chemical shift for many 


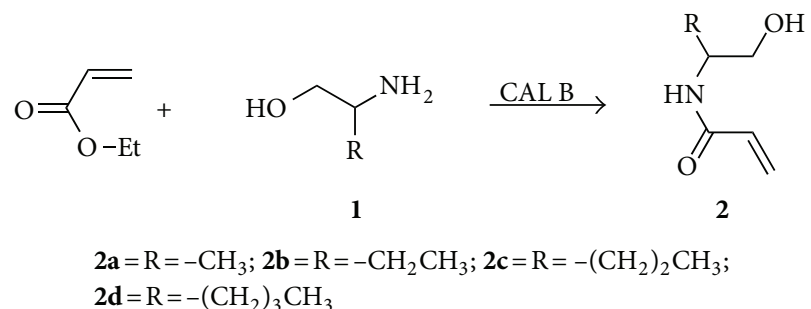

SCHeme 1: Lipase-catalyzed synthesis of $\mathbf{2 a - d}$.
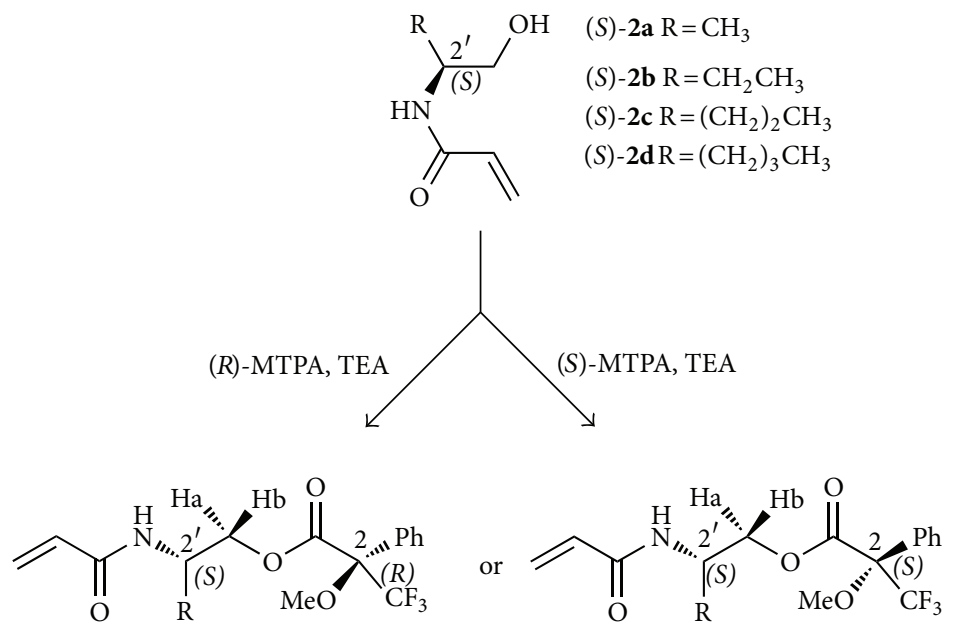

$(S)-\mathbf{3} \mathbf{a} \mathrm{R}=\mathrm{CH}_{3}$
$(S)-\mathbf{3} \mathbf{b ~ R}=\mathrm{CH}_{2} \mathrm{CH}_{3}$
$(S)-\mathbf{3} \mathbf{c ~ R}=\left(\mathrm{CH}_{2}\right)_{2} \mathrm{CH}_{3}$
$(S)-\mathbf{3} \mathbf{d} \mathrm{R}=\left(\mathrm{CH}_{2}\right)_{3} \mathrm{CH}_{3}$

(S) $-\mathbf{4 a} \mathrm{R}=\mathrm{CH}_{3}$

(S) $-\mathbf{4 b ~ R}=\mathrm{CH}_{2} \mathrm{CH}_{3}$

(S) $-\mathbf{4} \mathbf{c ~ R}=\left(\mathrm{CH}_{2}\right)_{2} \mathrm{CH}_{3}$

(S) $-\mathbf{4} \mathbf{d} \mathrm{R}=\left(\mathrm{CH}_{2}\right)_{3} \mathrm{CH}_{3}$

Scheme 2: MTPA esters (S)-3a-d and (S)-4a-d.

signals. Particularly, signals for diastereotopic protons $\mathrm{Hl}^{\prime}$ a and $\mathrm{Hl}^{\prime} \mathrm{b}$ of the $(R)$-MTPA amido ester $(S)$-3b were for the major isomer at $\delta 4.36$ and $4.37 \mathrm{ppm}$ and for the minor isomer at $\delta 4.33$ and 4.44 ppm (Figure 3 , Spectrum A). For the $(S)$ MTPA ester (S)-4b these signals are reversed, so that those corresponding to the major isomer are observed at $\delta 4.33$ and $4.44 \mathrm{ppm}$ and the signals for the minor isomer are observed at $\delta 4.36$ and 4.37 ppm (Figure 1, Spectrum B). The integration of the above-mentioned signals in both cases gave the same $35 \%$ ee value for $\mathbf{2} \mathbf{b}$.

The same procedure was applied to study the enantiomeric purity of the other three products $2 \mathrm{a}, \mathbf{2 c}$, and $\mathbf{2 d}$. Table 1 (columns 4 and 5) shows these results.

This pattern for the oxymethylene protons of chiral primary alcohols esterified with MTPA is according to previously published results on the determination of the absolute stereochemistry of a series of chiral primary alcohols with a methyl group at C-2 position [9] and chiral 1,3-dihidroxyketones [7]. In these works the absolute configuration of stereogenic centers was assigned by considering the $\Delta \delta$ between oxymethylene protons. Larger $\Delta \delta$ values of $(R)$ MTPA derivative were diagnosis for $R$ stereochemistry on the carbon vicinal to oxymethylene whereas smaller $\Delta \delta$ values of (R)-MTPA derivative were diagnosis for the opposite stereochemistry $(S)$. Accordingly, $(S)$-MTPA derivatives of $(R)$-primary alcohols showed smaller $\Delta \delta$ values for their oxymethylene proton signals than those prepared from $(S)$ primary alcohols.

For $(R)$-MTPA derivatives of chiral $N$-(2-hydroxyalkyl)acrylamides here reported, we found $\Delta \delta=0.01 \mathrm{ppm}$ for the major isomer and $\Delta \delta=0.11 \mathrm{ppm}$ for the minor isomer. This fact should indicate that the absolute stereochemistry of the major isomer is $\left(2 R, 2^{\prime} S\right)$ and therefore $(S)$ is the absolute configuration of the products $\mathbf{2 a - d}$.

On the other hand the stereoselective behavior of lipases towards hydrolysis of esters of chiral secondary alcohols has been extensively studied. The Kazlauskas rule is intended to predict the behavior of lipases in such cases and, according to this rule, lipases tend to hydrolyze esters of chiral secondary alcohols having absolute configuration $(R)$ faster than their enantiomer [13]. Lipases also showed the same stereochemical preference in transesterification and aminolysis reactions $[14,15]$.

This model takes into consideration that the substituent seniority can be correlated with substituent size, which is not always the case. The enormous diversity of substrates accepted by lipases and reaction conditions applied showed that this rule is not met in some circumstances $[16,17]$. 


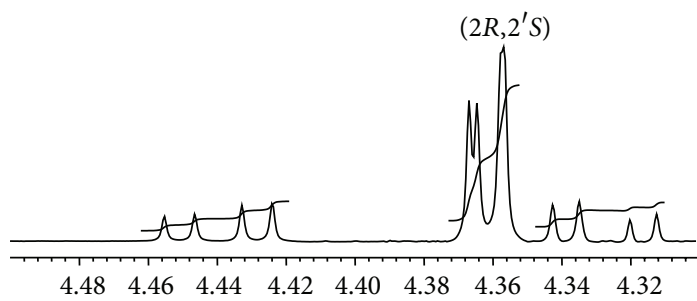

(a)

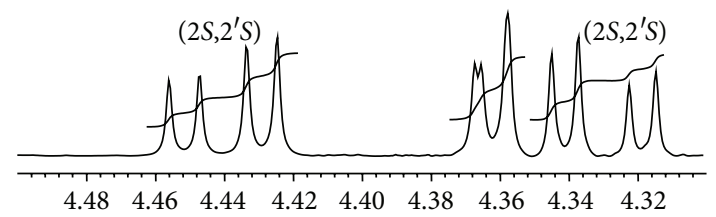

(b)

Figure $1:{ }^{1} \mathrm{H}$ NMR signals for diastereotopic protons $\mathrm{H1}^{\prime}$ a and $\mathrm{H1}^{\prime} \mathrm{b}$ in the (R)-MTPA amido ester (S)-3b (Spectrum A) and (S)-MTPA amido ester $(S)-\mathbf{4 b}$ (Spectrum B).

TABLE 1: Conformers of both diastereomers of $\mathbf{3 b}$.

\begin{tabular}{|c|c|c|c|c|c|}
\hline Compound & Diastereomer & Torl $\left({ }^{\circ}\right)$ & Tor2 $\left(^{\circ}\right)$ & $\triangle E(\mathrm{Kcal} / \mathrm{mol})$ & $\% \mathrm{P}$ \\
\hline \multirow{4}{*}{$(R)-\mathbf{3 b}$} & \multirow{4}{*}{$\left(2 R, 2^{\prime} R\right)$} & 178 & 1 & 1.54 & 4.2 \\
\hline & & -66 & 2 & 0.54 & 22.6 \\
\hline & & -70 & 5 & 0.00 & 56.5 \\
\hline & & 66 & 2 & 0.72 & 16.7 \\
\hline \multirow{11}{*}{$(S)-\mathbf{3 b}$} & \multirow{11}{*}{$\left(2 R, 2^{\prime} S\right)$} & 73 & -5 & 0.59 & 17.4 \\
\hline & & -49 & -4 & 1.70 & 2.6 \\
\hline & & 69 & 1 & 0.34 & 26.6 \\
\hline & & -76 & 4 & 1.88 & 2.0 \\
\hline & & -177 & 7 & 0.00 & 47.3 \\
\hline & & 168 & 4 & 1.60 & 3.1 \\
\hline & & 165 & 0 & 2.44 & 0.8 \\
\hline & & 162 & -2 & 3.02 & 0.3 \\
\hline & & -54 & 1 & 1.64 & 2.9 \\
\hline & & 156 & -108 & 2.99 & 0.3 \\
\hline & & -62 & -140 & 1.72 & 2.6 \\
\hline
\end{tabular}

For this reason, we considered that this primary conclusion should be submitted to further analysis, since this result seems difficult to be interpreted in terms of the Kazlauskas rule that predicted $(R)$-configuration. Therefore the stereochemical outcome of the enzymatic aminolysis of ethyl acrylate was not confirmed. Previous results on the enzyme-catalyzed transesterification of acrylates [18] derivatives of such compounds showed enantioselectivity towards $(R)$-enantiomer.

Furthermore, some authors reported that enzymecatalyzed hydrolysis and transesterification of alcohols [14] and hydrolysis of amide [19] derivatives of such compounds showed enantioselectivity towards $(R)$ - or $(S)$-enantiomer depending on the catalyst and the reaction conditions.

Moreover, we could not establish precisely if the reasoning from previously published results could also be applied in the determination of absolute stereochemistry of the chiral primary alcohols belonging to products $2 \mathbf{a}-\mathbf{d}$, by means of ${ }^{1} \mathrm{H}$ NMR analysis of their MTPA derivatives. Besides the experimental fact that the configuration of the chiral products was known, no clear evidence was found that could be interpreted or generalized on a molecular basis (i.e., evidence of conformational restrictions). For this reason, we decided to perform some experiments in silico in order to provide an independent explanation for experimental results.
Conformational search experiments were performed with MTPA derivatives $(S)-\mathbf{3 b}\left(2 S, 2^{\prime} S\right)$ and $(R)-\mathbf{3 b}\left(2 R, 2^{\prime} S\right)$. In these experiments the torsion angles $\mathrm{O}-\mathrm{Cl}^{\prime}-\mathrm{C} 2^{\prime}-\mathrm{C} 3^{\prime}$ (Torl) and $\mathrm{MeO}-\mathrm{C} 2-\mathrm{C} 1=\mathrm{O}$ (Tor2) (Figure 2 ) were varied in order to obtain the most stable conformers of both compounds and thus interpret the chemical shift differences observed between their oxymethylene protons and $\mathrm{H} 2{ }^{\prime}$ in ${ }^{1} \mathrm{H}$ NMR experiments.

As it can be observed in Table 1, up to nine stable conformers were found for $(S)-\mathbf{3 b}$ within $3 \mathrm{Kcal} / \mathrm{mol}$ above the global minimum. Most conformers had their methoxyl group synperiplanar to their carbonyl ester, which is according to previous calculations on other MTPA esters by DFT methods. However, many rotamers along $\mathrm{O}-\mathrm{Cl}^{\prime}$ and $\mathrm{Cl}^{\prime}-\mathrm{C}^{\prime}$ bond were found to be stable enough to be important contributions to conformer population. This fact explains the broader signals and lower $\Delta \delta$ values between oxymethylene protons for $(S)$-3b isomer. It was observed that signals at $\delta$ 4.36 and $4.37 \mathrm{ppm}$ are broad (more than $6 \mathrm{~Hz}$ wide) and not completely resolved.

On the other hand, only four stable conformers were found for the diastereomer $(R)-3 \mathbf{b}$. All of them had their methoxyl group synperiplanar to their carbonyl ester. Major contributions to the conformational population were the $\mathrm{H}_{2}^{\prime}$ 


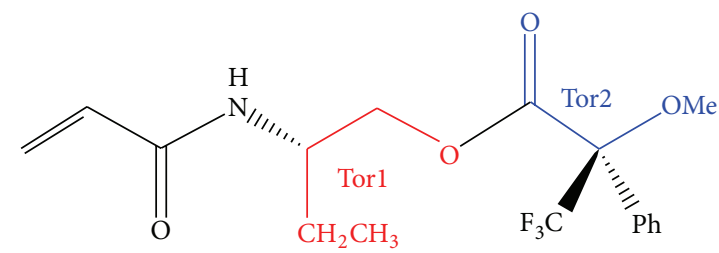

FIGURE 2: Torsion angles Torl (red and bold) and Tor2 (blue and bold) employed for conformational search of compound (S)-3b.

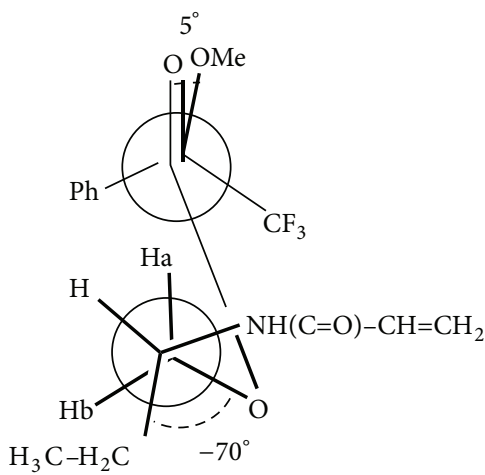

(a)

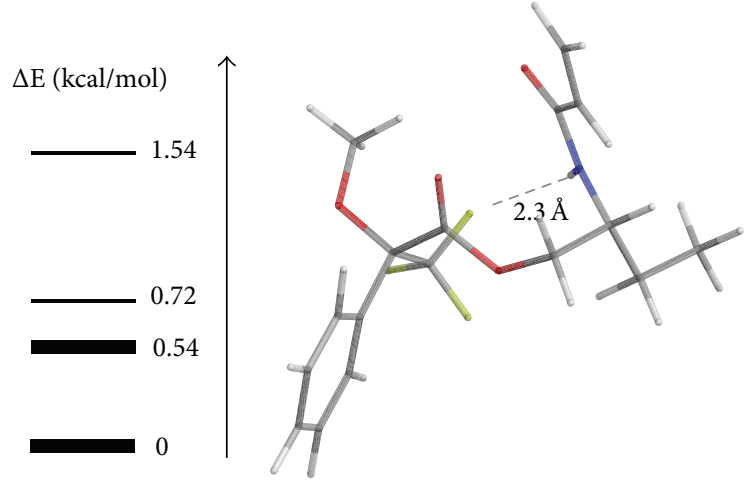

(b)

Figure 3: (a) Newman projections along the axes $\mathrm{C} 1-\mathrm{C} 2$ (up) and $\mathrm{C1}^{\prime}-\mathrm{C}^{\prime}$ (down) for the most stable conformer of $(R)$-3b. Torsion angles Torl and Tor2 are indicated. Major contributions to this type of conformation are highlighted in the energy level diagram on the right. (b) Picture of a 3D molecular render of the same conformer showing intramolecular hydrogen bonding between amide hydrogen and a fluorine atom (H-F distance: 2.3 angstrom).

antiperiplanar to oxygen attached to $\mathrm{Cl}^{\prime}$ (Figure 3). Two stable conformers have this conformation and they contribute to $79.1 \%$ of the total conformer population. Moreover, these conformers show one oxymethylene hydrogen $\left(\mathrm{Hl}^{\prime} \mathrm{b}\right)$ synperiplanar to the aromatic ring and the other $\left(\mathrm{Hl}^{\prime} \mathrm{a}\right)$ synperiplanar to the $\mathrm{C}=\mathrm{O}$ bond. These observations could explain the large difference of chemical shifts between both oxymethylene protons $(0.11 \mathrm{ppm})$ and the coupling constants observed for $\mathrm{H}^{\prime} \mathrm{a}-\mathrm{H} 2^{\prime}$ and $\mathrm{H}^{\prime} \mathrm{b}-\mathrm{H} 2^{\prime}(4.1 \mathrm{~Hz})$. The occurrence of intramolecular hydrogen bonding between the amide hydrogen and a fluorine atom was also confirmed for both conformers. We assume that this hydrogen bond plays a key role in conformer stability.

These results are difficult to assimilate to those predicted in Kazlauskas rule based on the size of the substituents in the stereocenter and designed to predict which enantiomer of a secondary alcohol reacts faster in enzyme catalyzed reactions. The rule is reliable with substrates having substituents which differ significantly in size.

In the acylation reaction of every chiral alkanolamine used in this work the enzyme showed an enantioselective behavior opposite to that described by Kazlauskas rule, preferably getting the product by reaction of alkanolamine with $(S)$ configuration instead of the $(R)$ predicted by the rule. In la the fact could be explained considering that the hydroxymethyl group is clearly larger than the methyl group, but in $\mathbf{1 b}$ ethyl and hydroxymethyl substituents are about the same size and compounds 1c and 1d have their alkyl substituent larger than their hydroxyalkyl substituent. In these two compounds the Kazlauskas rule could be applied in terms of substituent size.

The opposite configuration observed between the experimental results and that predicted by the rule could be attributed more likely to electronic effects than to steric hindrance. For instance, Maraite et al. showed that Pseudomonas stutzeri lipase stereoselectivity for benzoin acylation could be explained by hydrogen bonding between Tyr-54 hydroxyl group and carbonyl oxygen of the substrate [20]. A similar effect could be attained by hydrogen bonding between hydroxyl moiety of alkanolamine and the threonine-rich loop of residues 39-44 of CAL B. Therefore it could be suggested that the chemo- and enantioselectivity of the lipase-catalyzed $\mathrm{N}$-acylation of chiral alkanolamines must be driven by the presence of the hydroxyl group in one substituent rather than the difference in the substituent size.

\section{Conclusions}

In this work we have proposed a conformational model for MTPA esters of chiral N-(2-hydroxyalkyl)acrylamides. The in silico conformational analysis of the corresponding diastereomers $(R)-\mathbf{3} \mathbf{b}$ and $(S)$ - $\mathbf{3} \mathbf{b}$ showed that the differences in conformational restrictions, and consequently ${ }^{1} \mathrm{H}$ NMR signal splitting for oxymethylene protons, arose from specific intramolecular interactions rather than nonspecific steric hindrance. This analysis was also useful for explaining the chemical shift differences for both diastereomers and served 
for the validation of the stereochemical determination of chiral $N$-(2-hydroxyalkyl)acrylamides obtained by lipasecatalyzed resolution.

\section{Experimental}

4.1. General Remarks. ${ }^{1} \mathrm{H}$ NMR spectra were recorded in $\mathrm{CDCl}_{3}$ as solvent using a Bruker Avance II 500 spectrometer operating at $500 \mathrm{MHz}$. Chemical shifts are reported in $\delta$ units (ppm) relative to tetramethylsilane (TMS) set at $0 \mathrm{ppm}$, and coupling constants are given in hertz. The synthesis of $N$ (2-hydroxyalkyl)acrylamides $\mathbf{2 a - d}$ and their corresponding MTPA derivatives $\mathbf{3 a - d}$ and $\mathbf{4 a - d}$ were performed as described previously [11].

4.2. Molecular Modeling. The structures of $\left(2 R, 2^{\prime} R\right)-2^{\prime}-($ acryloylamino)butyl 3,3,3-trifluoro-2-methoxy-2-phenylpropanoate $(R)-3 \mathbf{b}$ and $\left(2 R, 2^{\prime} S\right)-2^{\prime}$-(acryloylamino)butyl 3,3,3trifluoro-2-methoxy-2-phenylpropanoate $(S)$-3b were submitted to conformational search using the molecular mechanics method $\mathrm{MM}+$ and a conformational search algorithm integrated on HyperChem 8.0. The selected torsions to vary were $\mathrm{O}-\mathrm{Cl}^{\prime}-\mathrm{C}_{2}^{\prime}-\mathrm{C}^{\prime}$ (Tor1) and $\mathrm{MeO}-\mathrm{C} 2-\mathrm{Cl}=\mathrm{O}$ (Tor2) and conformations of energies below $6 \mathrm{Kcal} / \mathrm{mol}$ over the global minimum were submitted to geometry optimization using Gamess [21]. Energies were minimized employing DFT method B3LYP using 6-31 g basis function. Solvent effect was simulated using the PCM method with the standard parameters for chloroform included in the software package. Optimized structures for each isomer were visualized using ChemBio3D Ultra 11.0 and overlaid in order to discard repeated structures.

\section{Conflict of Interests}

The authors declare that there is no conflict of interests regarding the publication of this paper.

\section{Acknowledgments}

The authors thank UBA X010, CONICET PIP 112-20080100801/09, and ANPCyT PICT 2005-32735 for partial financial support. Eduardo M. Rustoy, Alicia Baldessari, and Leandro N. Monsalve are research members of CONICET.

\section{References}

[1] M. Nyerges, D. Bendell, A. Arany et al., "Silver acetate-catalysed asymmetric 1,3-dipolar cycloadditions of imines and chiral acrylamides," Tetrahedron, vol. 61, no. 15, pp. 3745-3753, 2005.

[2] Y. Tian, W. Lu, Y. Che, L. B. Shen, L. M. Jiang, and Z. Q. Shen, "Synthesis and characterization of macroporous silica modified with optically active poly[N-(oxazolinylphenyl)acrylamide] derivatives for potential application as chiral stationary phases," Journal of Applied Polymer Science, vol. 115, no. 2, pp. 999-1007, 2010.

[3] J. Tobis, Y. Thomann, and J. C. Tiller, "Synthesis and characterization of chiral and thermo responsive amphiphilic conetworks," Polymer, vol. 51, no. 1, pp. 35-45, 2010.
[4] J. M. Seco, E. Quiñoá, and R. Riguera, “The assignment of absolute configuration by NMR," Chemical Reviews, vol. 104, no. 1, pp. 17-118, 2004.

[5] T. Pehk, E. Lippmaam, M. Lopp, A. Pajú, B. C. Borer, and R. J. K. Taylor, "Determination of the absolute configuration of chiral secondary alcohols; new advances using ${ }^{13} \mathrm{C}$ - and 2D-NMR spectroscopy," Tetrahedron Asymm, vol. 4, no. 7, pp. 1527-1532, 1993.

[6] K. Akiyama, S. Kawamoto, H. Fujimoto, and M. Ishibashi, "Absolute stereochemistry of TT-1 (rasfonin), an $\alpha$-pyrone-containing natural product from a fungus, Trichurus terrophilus," Tetrahedron Letters, vol. 44, no. 46, pp. 8427-8431, 2003.

[7] J. L. Galman and H. C. Hailes, "Application of a modified Mosher's method for the determination of enantiomeric ratio and absolute configuration at C-3 of chiral 1,3-dihydroxy ketones," Tetrahedron Asymmetry, vol. 20, no. 15, pp. 1828-1831, 2009.

[8] L. V. Parfenova, T. V. Berestova, T. V. Tyumkina et al., "Enantioselectivity of chiral zirconocenes as catalysts in alkene hydro-, carbo- and cycloalumination reactions," Tetrahedron Asymmetry, vol. 21, no. 3, pp. 299-310, 2010.

[9] M. Tsuda, Y. Toriyabe, T. Endo, and J. Kobayashi, "Application of modified Mosher's method for primary alcohols with a methyl group at C2 position," Chemical \& Pharmaceutical Bulletin, vol. 51, no. 4, pp. 448-451, 2003.

[10] E. M. Rustoy and A. Baldessari, "Chemoselective enzymatic preparation of N-hydroxyalkylacrylamides, monomers for hydrophilic polymer matrices," Journal of Molecular Catalysis B: Enzymatic, vol. 39, no. 1-4, pp. 50-54, 2006.

[11] L. N. Monsalve, E. M. Rustoy, and A. Baldessari, "Biocatalytic synthesis of chiral N-(2-hydroxyalkyl)-acrylamides," Biocatalysis and Biotransformation, vol. 29, no. 2-3, pp. 87-95, 2011.

[12] S. Puertas, R. Brieva, F. Rebolledo, and V. Gotor, "Lipase catalyzed aminolysis of ethyl propiolate and acrylic esters. Synthesis of chiral acrylamides," Tetrahedron, vol. 49, no. 19, pp. 40074014, 1993.

[13] R. J. Kazlauskas, A. N. E. Weissfloch, A. T. Rappaport, and L. A. Cuccia, "A rule to predict which enantiomer of a secondary alcohol reacts faster in reactions catalyzed by cholesterol esterase, lipase from Pseudomonas cepacia, and lipase from Candida rugosa," Journal of Organic Chemistry, vol. 56, no. 8, pp. 2656-2665, 1991.

[14] F. Francalanci, P. Cesti, W. Cabri, D. Bianchi, T. Martinengo, and M. Foà, "Lipase-catalyzed resolution of chiral 2-amino 1alcohols," Journal of Organic Chemistry, vol. 52, no. 23, pp. 50795082, 1987.

[15] J. González-Sabín, V. Gotor, and F. Rebolledo, "Enantioselective acylation of rac-2-phenylcycloalkanamines catalyzed by lipases," Tetrahedron: Asymmetry, vol. 16, no. 18, pp. 3070-3076, 2005.

[16] X. Xia, Y.-H. Wang, B. Yang, and X. Wang, "Wheat germ lipase catalyzed kinetic resolution of secondary alcohols in nonaqueous media," Biotechnology Letters, vol. 31, no. 1, pp. 83-87, 2009.

[17] P. Hoyos, V. Pace, J. V. Sinisterra, and A. R. Alcántara, "Chemoenzymatic synthesis of chiral unsymmetrical benzoin esters," Tetrahedron, vol. 67, no. 38, pp. 7321-7329, 2011.

[18] S. Akai, T. Naka, S. Omura et al., "Lipase-catalyzed domino kinetic resolution/intramolecular Diels-Alder reaction: one-pot synthesis of optically active 7-oxabicyclo[2.2.1]heptenes from furfuryl alcohols and $\beta$-substituted acrylic acids," Chemistry: $A$ European Journal, vol. 8, pp. 4255-4264, 2002. 
[19] N. W. Fadnavis, M. Sharfuddin, and S. K. Vadivel, "Resolution of racemic 2-amino-1-butanol with immobilised penicillin G acylase," Tetrahedron Asymmetry, vol.10, no. 23, pp. 4495-4500, 1999.

[20] A. Maraite, P. Hoyos, J. D. Carballeira, A. C. Cabrera, M. B. Ansorge-Schumacher, and A. R. Alcántara, "Lipase from Pseudomonas stutzeri: purification, homology modelling and rational explanation of the substrate binding mode," Journal of Molecular Catalysis B: Enzymatic, vol. 87, pp. 88-98, 2013.

[21] M. W. Schmidt, K. K. Baldridge, J. A. Boatz et al., "General atomic and molecular electronic structure system," Journal of Computational Chemistry, vol. 14, no. 11, pp. 1347-1363, 1993. 

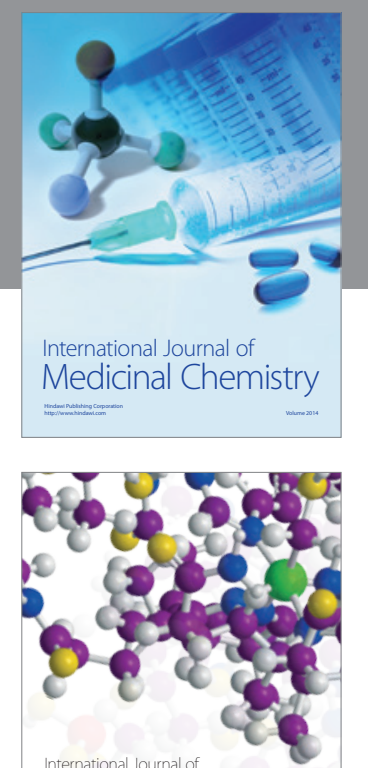

\section{Carbohydrate} Chemistry

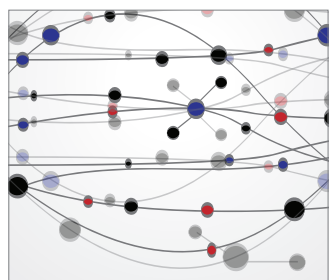

The Scientific World Journal
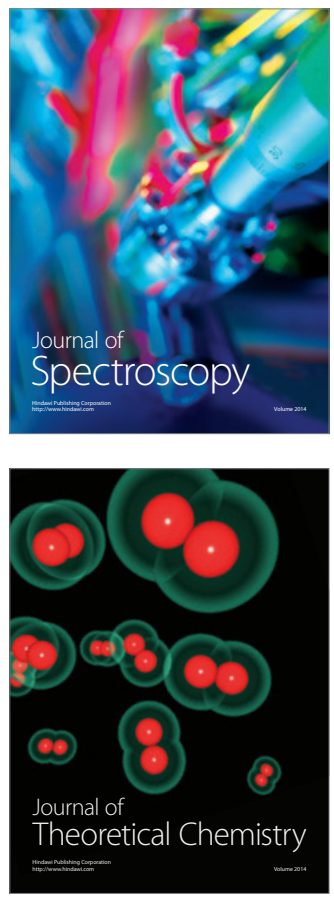
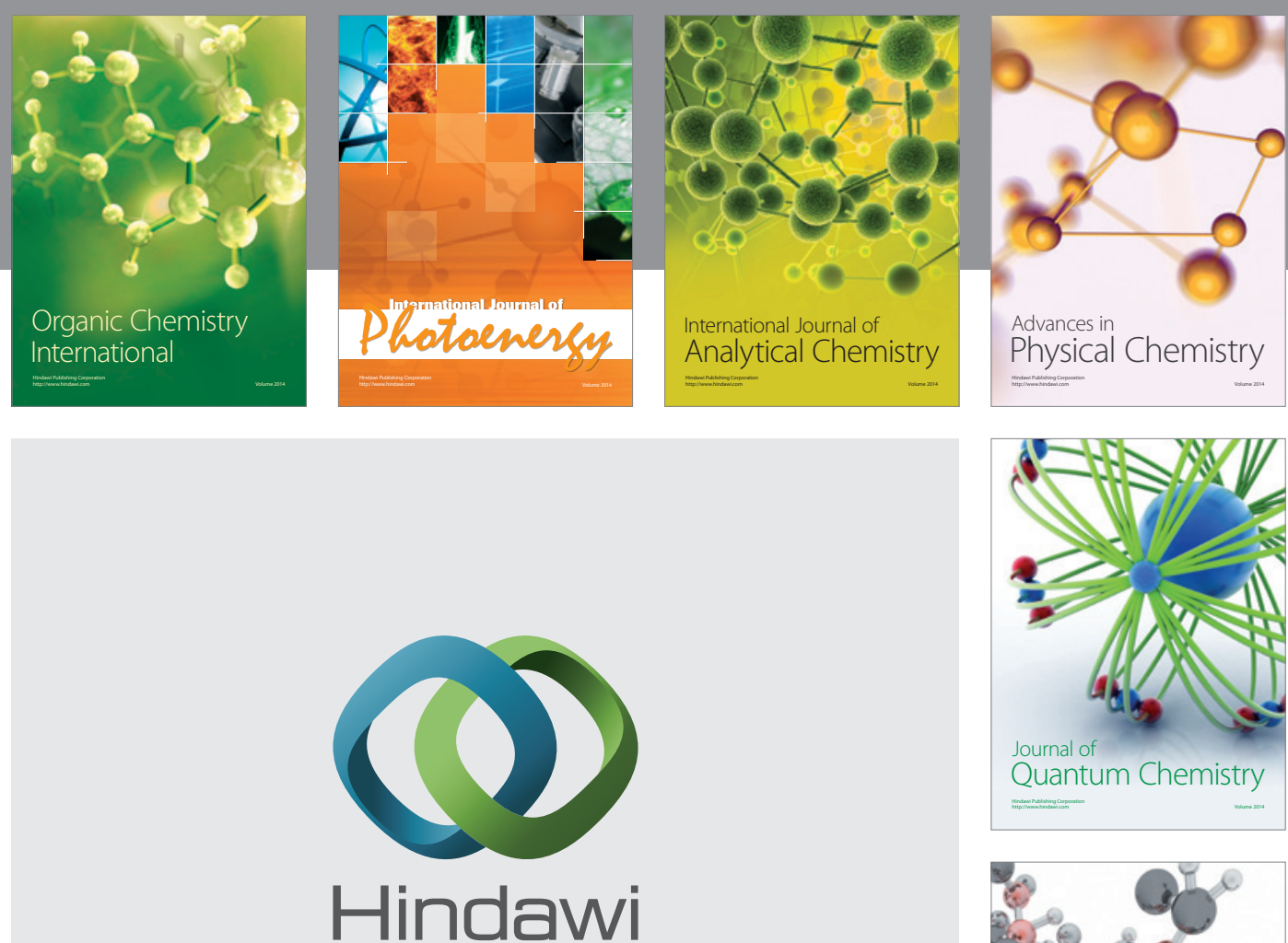

Submit your manuscripts at

http://www.hindawi.com

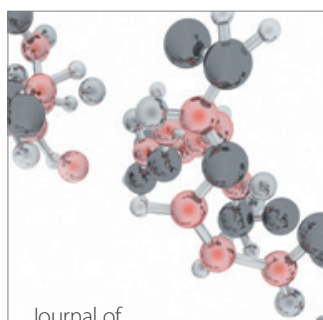

Analytical Methods

in Chemistry

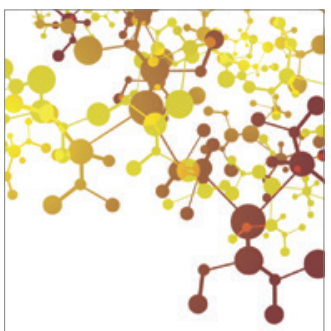

Journal of

Applied Chemistry

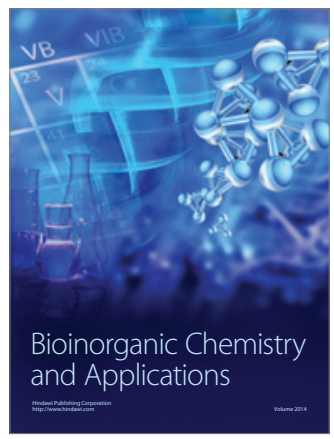

Inorganic Chemistry
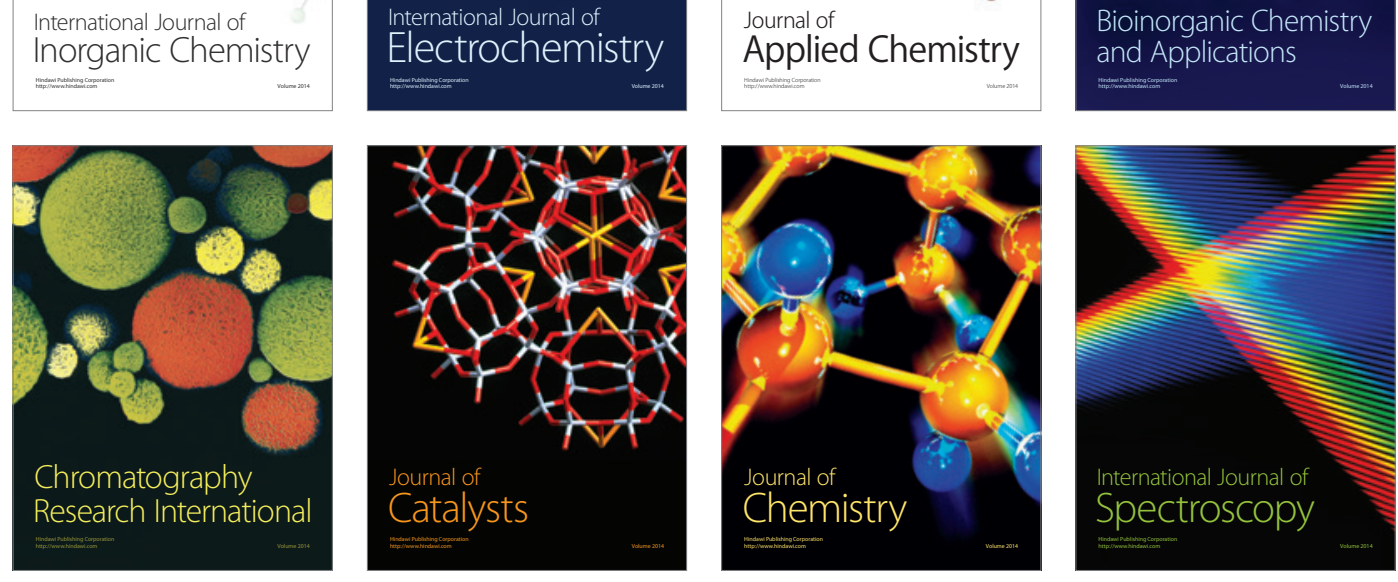